\title{
A Compact Dual-/Multi-Band Wireless LAN Antenna
}

\author{
Nader Behdad ${ }^{*}$ and Kamal Sarabandi \\ Department of Electrical Engineering and Computer Science \\ University of Michigan, Ann Arbor, MI, 48109-2122 \\ behdad@eecs.umich.edu, saraband@eecs.umich.edu
}

\section{INTRODUCTION}

Recent advancements in wireless technology and significant growth in consumer demands have significantly increased the popularity of wireless networks. Nowadays wireless access to the Internet is becoming a necessity of life much faster than cell phones became an essential part of our day to day lives a decade ago. In order to regulate the interaction of different devices in such wireless networks, standards such as IEEE 802.11, WiFi, Bluetooth, HomeRF, and HiperLAN have been developed and have been or are currently being adopted in different countries. These different standards have different requirements and use different frequency bands mainly around the $2.4 \mathrm{GHz}$ and $5 \mathrm{GHz}$ bands. Many of the commercial systems are being designed to be compatible with more than one of the aforementioned standards which operate at different frequency bands e.g., IEEE 802.11 and 802.11a. Thus, the RF circuits and antennas designed for such systems must also be able to work at different frequency bands.

It was recently shown that, a relatively wide rectangular slot antenna with an aspect ratio (width to length, W/L) between 0.15 and 0.25 can be designed to show a double resonant behavior when it is fed with a microstrip line near one edge [1]. The two resonances can be chosen such that a wideband or a dual-band antenna is obtained. In this paper, we extend this idea to design a wideband and dual-band microstrip-fed notch shaped antenna which can easily be fabricated on the printed circuit board of the device. In particular a dual-band antenna is developed that is compatible with all of the existing wireless LAN standards. Furthermore, it is shown that two such antennas can be coupled together using a single feed to achieve a compact antenna with a very large bandwidth.

\section{ANTENNA CONFIGURATION AND DESIGN PROCEDURE}

A relatively wide slot antenna, with an aspect ratio between 0.15 and 0.25 , fed with an off-centered microstrip line can be designed to show a double-resonant behavior. The first resonance is the normal resonance of the antenna and is inversely proportional to the antenna length. The second resonance, however, can be attributed to a fictitious short circuit that occurs near the microstrip feed line as described in [1]. The frequency of this fictitious resonance is determined by the location of the microstrip feed and can be chosen such that a wideband or dualband antenna is obtained. The electric field distributions of the antenna at these two resonances are shown in Figures 1(a) and 1(b). It is observed that the field distributions at these two resonances are similar to each other and hence, the antenna has similar radiation characteristics at both bands. 
In this paper we apply the same technique to a notch antenna, which resembles a quarter wave slot antenna, and then modify its topology to obtain a modified microstrip-fed notch antenna. Fig. 2(a) shows a rectangular notch antenna fed by an open-circuited microstrip line. The antenna is matched to the line impedance $(50 \Omega)$ by choosing the appropriate location for the feed $\left(L_{s}\right)$ and the length of the open-circuited stub, $L_{m}$ [2]. The notch slot, which is located in the middle of the ground plane, is moved to the edge of the ground plane, as shown in Fig. 2(b), and the excess metal to the right of the slot is removed to obtain the final topology of the antenna, as shown in Fig. 2(c). Similar to the antennas studied in [1], the location of the microstrip feed can be chosen such that a broadband or a dual-band operation is obtained. Using this technique, a dual-band antenna is designed on a $0.5 \mathrm{~mm}$ thick substrate with dielectric constant of 3.4 and overall substrate dimensions of $80 \times 50 \mathrm{~mm}^{2}$. The substrate dimensions are equal to the dimensions of a standard PCMCIA card, which is used in laptop computers. Fig. 3 shows details of the topology of the antenna and its dimensions.

\section{RESULTS AND DISCUSSION}

The dual-band antenna, shown in Fig. 3, is simulated using IE3D [3] and fabricated on a $0.5 \mathrm{~mm}$ thick $80 \times 50 \mathrm{~mm}^{2}$ RO $4350 \mathrm{~B}$ substrate from Rogers Corp. The simulated and measured reflection coefficients of this antenna are shown in Fig. 5. As can be observed from this figure, the antenna has two bands of operation, over which its VSWR is smaller than 2 , in the ranges of $2.35 \mathrm{GHz}$ $2.5 \mathrm{GHz}$ and $4.64 \mathrm{GHz}-5.92 \mathrm{GHz}$. These bands include the designated frequency bands of the IEEE 802.11, 802.11a, Bluetooth, HiperLAN, and HomeRF standards. The co- and cross-polarized radiation patterns of the antenna in the Eand $\mathrm{H}$ - Plane are measured in the anechoic chamber of the University of Michigan and presented in Figures 7 and 8 respectively. Figure 7 shows the measured antenna patterns in the E-plane at $2.4 \mathrm{GHz}$ and $5.8 \mathrm{GHz}$ and Figure 8 shows the measured patterns in the $\mathrm{H}$-plane at these frequencies. It is observed that the radiation patterns of the antenna at the two bands are similar to each other and the cross polarization levels are relatively small. The gain of the antenna is measured using a double-ridged horn antenna and is reported in Table I.

Similar to the results reported in [1], the response of the antenna is a function of the location of the microstrip feed, $L_{s}$ For large $L_{s}$ values $\left(L_{s} / L>0.2\right)$, the antenna operates in a dual-band mode. As $L_{S}$ is decreased $\left(L_{s} / L<0.2\right)$, however, the antenna enters in a wideband mode and bandwidths in the range of $30 \%-40 \%$ can easily be achieved from one single element. It is also possible to couple two such antennas in a topology shown in Fig. 4 to obtain an antenna with a much larger bandwidth. In this case, one antenna is fed with a microstrip line and the other one is parasitically coupled to it. The dimensions of this antenna are also shown in Fig. 4. As is observed from this figure, the two antennas have different lengths and cover different parts of frequency bands. Wideband matching is obtained by tuning the length of the open circuited microstrip stub, $L_{m}$. The antenna is fabricated on a similar $0.5 \mathrm{~mm}$ thick $\mathrm{RO} 4350 \mathrm{~B}$ substrate with a total 
substrate area of $80 \times 50 \mathrm{~mm}^{2}$. From the measured $\mathrm{S}_{11}$ of this antenna, which is shown in Fig. 6, it is observed that the antenna has a VSWR smaller than 2 over a bandwidth ranging from $2.37 \mathrm{GHz}$ to $4.38 \mathrm{GHz}$ or equivalently $1.85: 1$. The radiation patterns of this antenna are measured at three different frequencies across its entire band of operation and will be presented in the symposium. The antenna gain is also measured in the anechoic chamber of the University of Michiganand is presented in Table I.

\begin{tabular}{|c|c|c|c|c|}
\hline \multirow{3}{*}{ WLAN Antenna } & \multicolumn{4}{|c|}{ Measured Gain } \\
\hline & $2.5 \mathrm{GHz}$ & $4.6 \mathrm{GHz}$ & $5.2 \mathrm{GHz}$ & $5.8 \mathrm{GHz}$ \\
\hline & $1.9 \mathrm{dBi}$ & $0.7 \mathrm{dBi}$ & $1.0 \mathrm{dBi}$ & $1.1 \mathrm{dBi}$ \\
\hline \multirow[t]{2}{*}{ Broadband antenna } & $2.5 \mathrm{GHz}$ & \multicolumn{2}{|c|}{$3.5 \mathrm{GHz}$} & $4.5 \mathrm{GHz}$ \\
\hline & $1.1 \mathrm{~dB}$ & \multicolumn{2}{|c|}{$0.5 \mathrm{~dB}$} & \\
\hline
\end{tabular}

Table I. Measured gain of the WLAN and the double-element broadband antennas.

\section{CONCLUSIONS}

Dual-band and broadband characteristics of a certain class of microstrip-fed slot antennas are expanded to a special class of notch antennas and a singleelement dual-band antenna for WLAN applications is developed. The antenna uses a simple feeding and matching mechanism and has similar radiation patterns at both bands. The same antenna topology can be used to design single-element wideband antennas by appropriately choosing the location of the feed. A prototype consisting of two such radiators is developed and shown to have a very wide bandwidth (1.85:1) while occupying a small area.

\section{REFERENCES}

[1] Behdad, N. and K. Sarabandi, "A Wideband Slot Antenna Design Employing A Fictitious Short Circuit Concept", IEEE Trans. Ant. and Prop., Vol. 53, pp. 475-482.

[2] Behdad, N. and K. Sarabandi, "Bandwidth Enhancement and Further Size Reduction of a Class of Miniaturized Slot Antennas", IEEE Trans. Ant. and Prop., Vol. 42, pp. 1928-1935.

[3] "IE3D Electromagnetic Simulation and Optimization Software", Zeland, Inc.

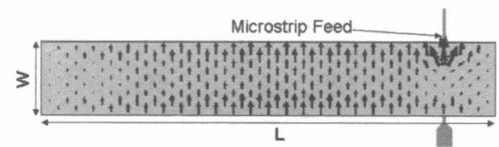

(a)

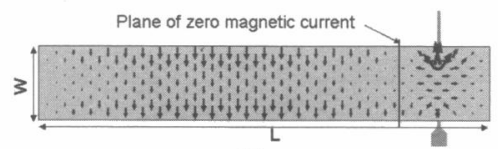

(b)

Fig. 1. The electric field distribution of a relatively wide microstrip-fed slot antenna at (a) its first normal resonance and (b) the second fictitious resonance.

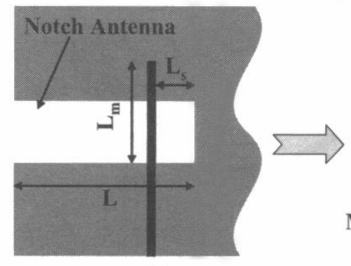

(a)

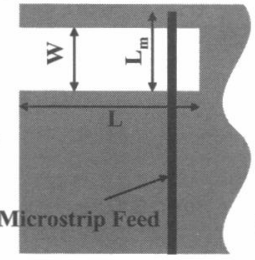

(b)

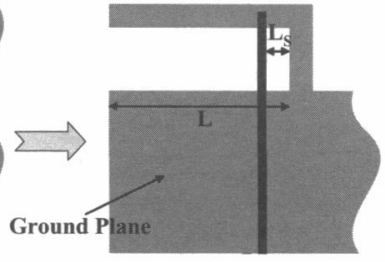

(c)

Fig. 2. Transformation of a microstrip-fed notch antenna to the proposed antenna. 


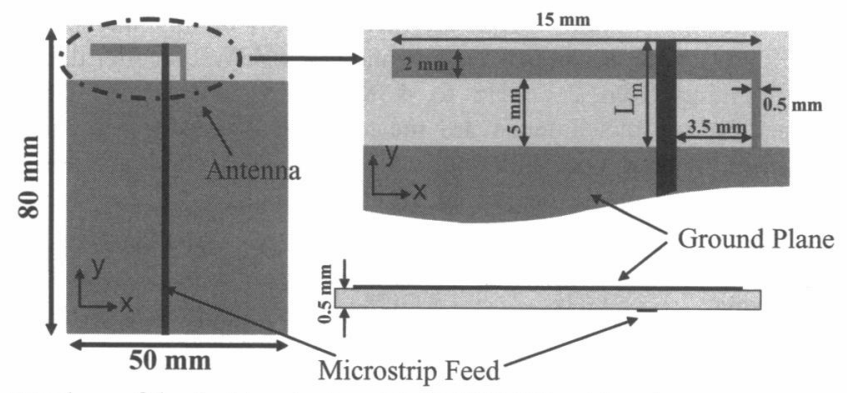

Fig. 3. Topology of the dual-band microstrip-fed WLAN notch antenna.

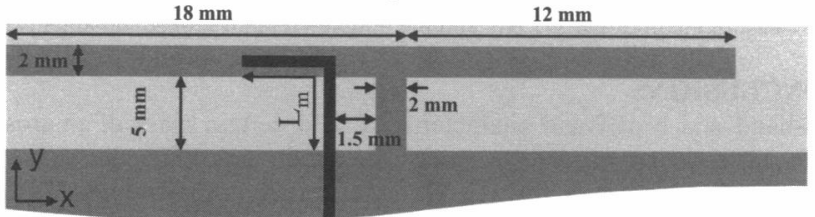

Fig. 4. Topology of the broad-band, double-element, microstrip-fed notch antenna.
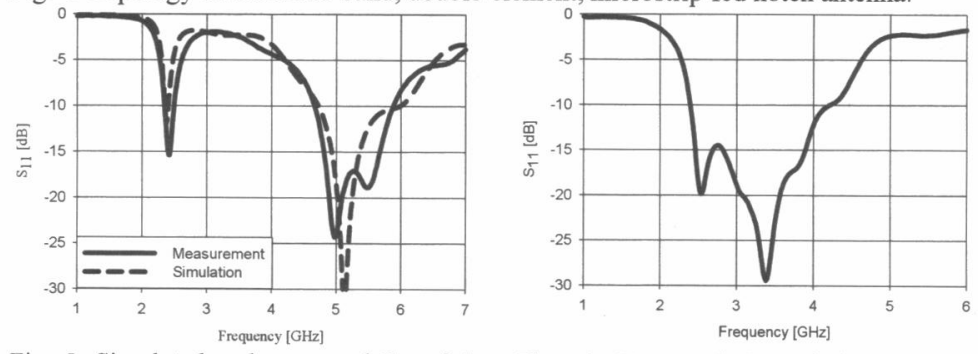

Fig. 5. Simulated and measured $S_{11}$ of the dual-band antenna shown in Fig. 3.

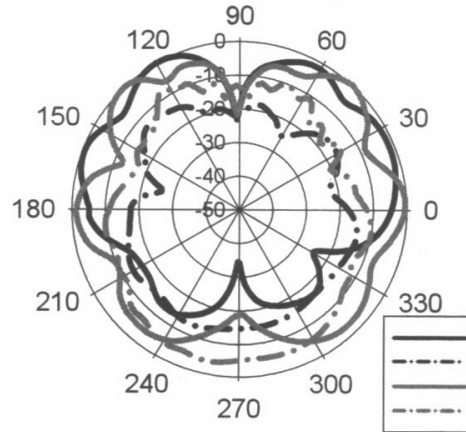

Fig. 7. Measured radiation patterns of the WLAN antenna in the E-Plane ( $y-z$ plane)
Fig. 6. Measured $S_{11}$ of the broadband antenna shown in Fig. 4

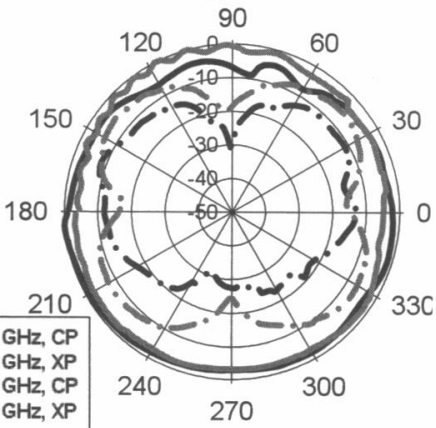

Fig. 8. Measured radiation patterns of the WLAN antenna in the H-Plane ( $\mathrm{x}-\mathrm{z}$ plane) 